\title{
Observation of Kelvin-Helmholtz instabilities and gravity waves in the summer mesopause above Andenes in Northern Norway
}

\author{
Gunter Stober $^{1}$, Svenja Sommer ${ }^{1, a}$, Carsten Schult ${ }^{1}$, Ralph Latteck ${ }^{1}$, and Jorge L. Chau ${ }^{1}$ \\ ${ }^{1}$ Leibniz Institute of Atmospheric Physics at the University Rostock, Schlossstr. 6, 18225 Kühlungsborn, Germany \\ a now at: Fraunhofer Institute for High Frequency Physics and Radar Techniques, \\ Fraunhoferstr. 20, 53343 Wachtberg, Germany
}

Correspondence: Gunter Stober (stober@iap-kborn.de)

Received: 13 December 2017 - Discussion started: 2 January 2018

Revised: 12 April 2018 - Accepted: 25 April 2018 - Published: 14 May 2018

\begin{abstract}
We present observations obtained with the Middle Atmosphere Alomar Radar System (MAARSY) to investigate short-period wave-like features using polar mesospheric summer echoes (PMSEs) as a tracer for the neutral dynamics. We conducted a multibeam experiment including 67 different beam directions during a 9-day campaign in June 2013. We identified two Kelvin-Helmholtz instability (KHI) events from the signal morphology of PMSE. The MAARSY observations are complemented by collocated meteor radar wind data to determine the mesoscale gravity wave activity and the vertical structure of the wind field above the PMSE. The KHIs occurred in a strong shear flow with Richardson numbers $R i<0.25$. In addition, we observed 15 wave-like events in our MAARSY multibeam observations applying a sophisticated decomposition of the radial velocity measurements using volume velocity processing. We retrieved the horizontal wavelength, intrinsic frequency, propagation direction, and phase speed from the horizontally resolved wind variability for 15 events. These events showed horizontal wavelengths between 20 and $40 \mathrm{~km}$, vertical wavelengths between 5 and $10 \mathrm{~km}$, and rather high intrinsic phase speeds between 45 and $85 \mathrm{~m} \mathrm{~s}^{-1}$ with intrinsic periods of 5-10 min.
\end{abstract}

\section{Introduction}

The middle atmosphere is a highly variable atmospheric region driven by a variety of waves. In particular, the dynamics of the mesosphere-lower thermosphere (MLT) region is characterized by waves spanning various temporal and spatial scales, e.g., planetary waves, tides, and gravity waves
(GWs). Our current knowledge about the energy dissipation of breaking mesoscale GWs at the MLT is limited due to the lack of continuous high-resolution (spatial and temporal) temperature and wind measurements at these altitudes.

Optical observations, such as lidar or airglow imagers, depend on the weather conditions (cloud-free conditions) and are often restricted to nighttime measurements only. Airglow imagers (e.g., Hecht et al., 2000, 2005, 2007; Suzuki et al., 2013; Wüst et al., 2017) and the mesospheric temperature mapper (Taylor et al., 2007) have the ability to resolve the horizontal structure in the field of view as well as to obtain information about the temporal evolution of mesoscale GWs or wave-like structures, often called ripples (Hecht et al., 2007). These ripples are excited when mesoscale GWs break and dissipate their energy and momentum. The nature of these ripple structures is associated with either convective or dynamical instabilities. Dynamical instabilities often evolve into Kelvin-Helmholtz instabilities (KHIs), whereas the convective instability has its origin in superadiabatic temperature gradients (Hecht et al., 2005). Airglow observations as well as models (Horinouchi et al., 2002) suggest that KHI can generate secondary instabilities of a convective nature. Although optical measurements provide valuable information on such small-scale dynamics, they are limited to nighttime and cloud-free conditions. In addition, airglow observations are lacking precise altitude information.

Although observations of KHIs have been reported previously using very high-frequency (VHF) radars (Reid et al., 1987), we try to identify such events using polar mesospheric summer echoes (PMSEs) as a tracer. There are several studies of KHIs from radar observations in the troposphere (e.g., 
Klostermeyer and Rüster, 1980, 1981; Fukao et al., 2011) or in the equatorial mesosphere (e.g., Lehmacher et al., 2007, 2009). Optical observations of noctilucent clouds (NLCs) (e.g., Demissie et al., 2014; Baumgarten and Fritts, 2014; Fritts et al., 2014), which are closely related to PMSE, show that KHIs occur rather frequently in the summer mesopause at polar latitudes and, hence, might also be seen using PMSE as a tracer.

Although the PMSE occurrence rate reaches almost $100 \%$ during the summer months at Andenes with MAARSY (Latteck and Bremer, 2012), the morphology itself is rather variable. In particular, the layering within PMSE is significant (Sommer et al., 2014) and has to be taken into account when PMSE is used as a tracer for the MLT dynamics. The PMSE layer is affected by tides and GWs, leading to characteristic altitude variations with a minimum occurrence of better strength in the afternoon between 14:00 and 18:00 UTC.

In this paper we present measurements under daylight conditions with a high spatial and temporal resolution using a multibeam radar experiment. The observations were conducted with the Middle Atmosphere Alomar Radar System (MAARSY) in Northern Norway $\left(69.30^{\circ} \mathrm{N}, 16.04^{\circ} \mathrm{E}\right)$ during summer 2013. PMSEs are a common phenomenon at this latitude and are suitable tracers of neutral dynamics (e.g., Chilson et al., 2002; Stober et al., 2013).

KHIs are investigated from the signal morphology of the PMSE as well as from the obtained Doppler measurements. Our Doppler velocity measurements permit us to determine the amplitude of the instability and to estimate the characteristic scales during a strong shear flow. The PMSE wind observations are complemented by meteor radar winds in order to access the mean winds above and below the PMSE layer and to estimate the mesoscale stability computing the Richardson number (Ri) taking NRLMSISE-00 as background temperature (Picone et al., 2002). In the second part of the paper we investigate 15 events with wave-like features using the imaging capabilities of the radar system to obtain horizontally resolved radial velocity images, which are analyzed with respect to the propagation direction, horizontal wavelength, and phase speed (Stober et al., 2013).

The paper is structured as follows. A short summary of the technical details of MAARSY as well as the experiments are presented in Sect. 2, also including a brief description of the Andenes meteor radar. The wind analysis is outlined in Sect. 3. Section 4 contains a description of the analysis of two GW-induced KHI events seen in the morphology of a PMSE, and we review the GW analysis from horizontally resolved radial velocities and present the obtained GW properties (observed and intrinsic phase speed, observed and intrinsic period, horizontal and vertical wavelength). Our results are discussed and related to other observations in Sect. 5. Finally, we summarize and conclude our results in Sect. 6.

\section{Experimental setup}

MAARSY is located at the Northern Norwegian island of Andøya $\left(69.30^{\circ} \mathrm{N}, 16.04^{\circ} \mathrm{E}\right)$. The system operates within the VHF band at 53.5 MHz. The radar employs an active phased array consisting of 433 individual antennas. Each antenna is connected to its own transceiver module, which is freely adjustable in phase, power, and frequency (within the assigned $2 \mathrm{MHz}$ bandwidth around the carrier frequency). MAARSY has a peak power of $866 \mathrm{~kW}$ and a beam width of $3.6^{\circ}$. The beam is freely steerable within off-zenith angles up to $35^{\circ}$ without generating grating lobes. A more detailed description of the radar is given in Latteck et al. (2012) and an overview of wind field analysis using multibeam experiments can be found in Stober et al. (2013).

In summer 2013, MAARSY conducted several multibeam experiments to provide systematic scans of the horizontal structure of PMSE using 67 unique beam pointing directions. The experiments were optimized to ensure a horizontal coverage of $80 \mathrm{~km}$ in diameter while keeping a fast enough sampling speed to obtain reliable Doppler measurements. A complete scan of the observation volume consisted of four experiments with 17 beams each. Each experiment did contain the vertical beam and 16 oblique beams. Figure 1 shows the beam positions for the complete sequence as a projection above the North Norwegian shoreline (black lines). The red circles denote the diameter of the illuminated area assuming a $3.6^{\circ}$ beam width.

The total time resolution between successive scans with the multibeam experiments was $3 \mathrm{~min} 35 \mathrm{~s}$. The shortest GW period that could exist at the PMSE altitude is given by the Brunt-Väisälä period, which is approximately $4 \mathrm{~min}$ at the summer polar mesopause. Given that the vertical beam is sampled at a higher temporal resolution (it is included in each experiment), it is possible to resolve even higher periodicities of approximately $1 \mathrm{~min}$. So far, the spatial and temporal resolution of the multibeam observations is sufficient to resolve short-period wave-like features. The images derived from the multibeam experiments permit us to directly access the intrinsic GW properties similar to airglow observations.

\section{Data analysis}

A summary of the experiment configuration is given in Table 1 . We analyzed the recorded raw data with regard to the signal-to-noise ratio (SNR), the radial velocity, and the spectral width using four incoherent integrations. Further, we obtain the statistical uncertainties from a truncated Gaussian fit to the spectra. The fitting routine is based upon the concept presented in Kudeki et al. (1999), Sheth et al. (2006), and Chau and Kudeki (2006). This spectral Gaussian fitting takes the effects of the rectangular window and the temporal sampling into account. 


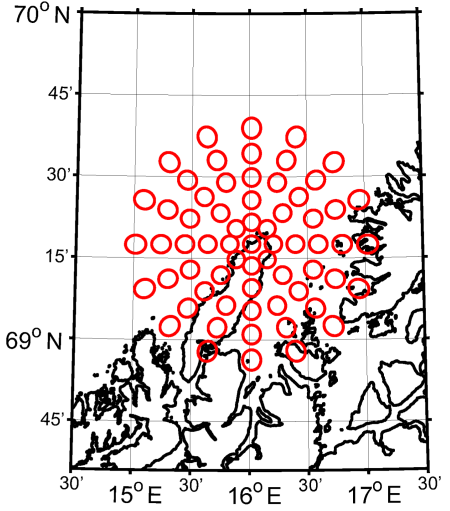

Figure 1. Projection of MAARSY beam positions for the multibeam experiments during summer 2013. The red circles show the illuminated radar beam area assuming a beam width of $3.6^{\circ}$ at $84 \mathrm{~km}$ altitude. The black lines are the shoreline around the North Norwegian island Andøya.

Table 1. Experiment parameters (PRF: pulse repetition frequency; CI: coherent integrations; acq: acquisition; pulse code: coco - 16 bit complementary code).

\begin{tabular}{|c|c|c|c|c|}
\hline Parameter & Exp 1 & $\operatorname{Exp} 2$ & Exp 3 & Exp 4 \\
\hline PRF (Hz) & 1250 & 1250 & 1250 & 1250 \\
\hline sampling resolution $(\mathrm{m})$ & 300 & 300 & 300 & 300 \\
\hline $\mathrm{CI}$ & 2 & 2 & 2 & 2 \\
\hline Pulse code & coco & coco & coco & coco \\
\hline Number of beams & 17 & 17 & 17 & 17 \\
\hline Off-zenith angles & $0,5,10^{\circ}$ & $0,15^{\circ}$ & $0,20^{\circ}$ & $0,25^{\circ}$ \\
\hline Nyquist velocity $\left(\mathrm{m} \mathrm{s}^{-1}\right)$ & 22.5 & 22.5 & 22.5 & 22.5 \\
\hline Data points & 256 & 256 & 256 & 256 \\
\hline Acq. time (s) & 25 & 25 & 25 & 25 \\
\hline
\end{tabular}

In Fig. 2 in the upper two panels we show contour plots of the radial velocities as well as their associated statistical uncertainties. We removed potential meteors to avoid a contamination of the measurements. Meteors are removed by checking all data points with an SNR $>-7 \mathrm{~dB}$, if there are other adjacent points with a SNR larger than our noise floor (approximately SNR $<-7.5 \mathrm{~dB}$ ). If there is only one point with an enhanced SNR and all surrounding ones are smaller or comparable to the noise floor $\pm 0.2 \mathrm{~dB}$, we consider this measurement to be contaminated by a meteor. Further, we suppressed a potential side lobe contamination at the edges of the PMSE layer by using the interferometry and assumed consistency in the vertical profile of the radial velocities. If there is a jump in the vertical profile of more than $6 \mathrm{~m} \mathrm{~s}^{-1}$ from the core region towards the edges between adjacent pixels, we removed these measurements.

The lower panels in Fig. 2 show a histogram of statistical uncertainties of the radial velocity and a SNR vs. radial statistical uncertainty scatterplot. The histogram peaks at a statistical uncertainty of $0.17 \mathrm{~m} \mathrm{~s}^{-1}$ and has a median of
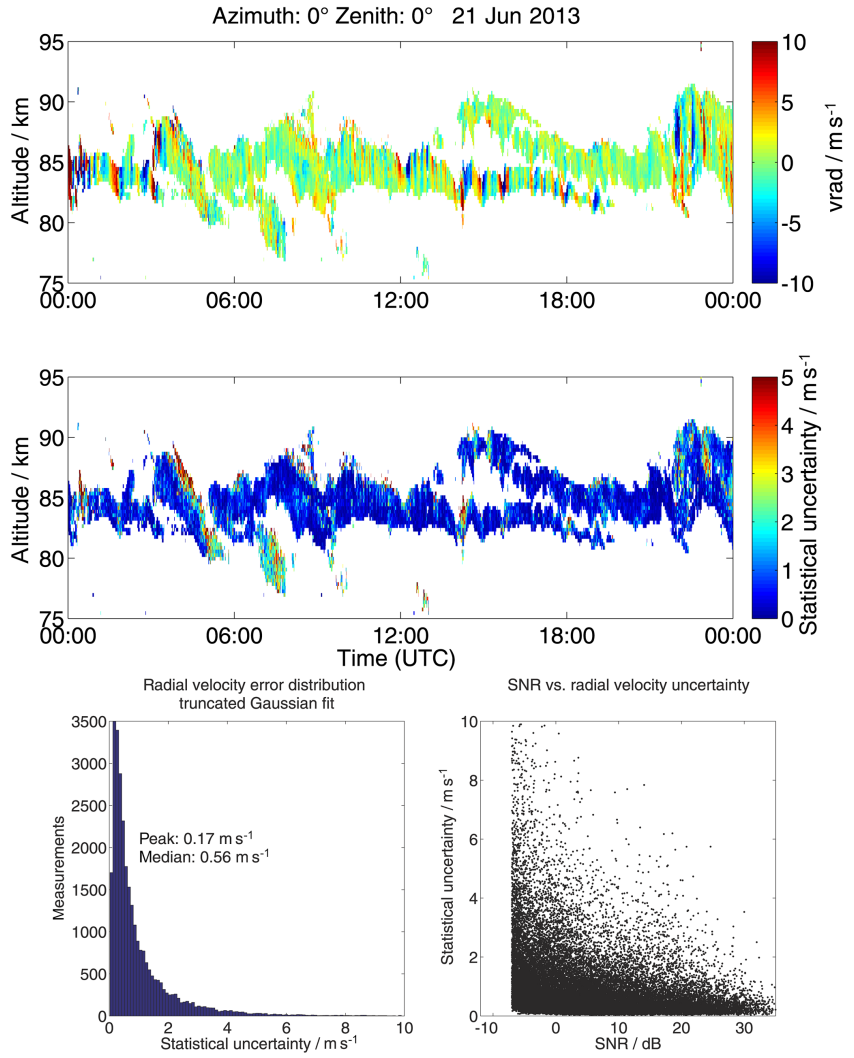

Figure 2. Stack plot of the radial velocity measurements with MAARSY. The lower panels show the color-coded statistical uncertainties of the radial velocity measurement.

about $0.56 \mathrm{~m} \mathrm{~s}^{-1}$. We truncated the contour plot color scale at $5 \mathrm{~m} \mathrm{~s}^{-1}$ as the histogram shows almost no radial velocity uncertainties larger than $5 \mathrm{~m} \mathrm{~s}^{-1}$. The SNR vs. statistical uncertainty radial velocity scatterplot further visualizes the L shape, which means that large errors are often associated with low SNR measurements, as is expected.

MAARSY has a multichannel receiver system, which is used for coherent radar imaging (CRI) (e.g., Woodman, 1997; Chilson et al., 2002; Sommer et al., 2014). When PMSEs have relative steep gradients at the edges of the layer, the CRI technique is useful to correct for beam filling effects leading to differences between the nominal beam pointing direction and the strongest returned signal (Sommer et al., 2014). This is of particular relevance for the oblique beams with off-zenith angles of more than $10^{\circ}$ as there could be a deviation of several degrees from the nominal beam pointing direction causing substantial errors in the derived horizontal wind velocities and altitude errors of up to $2 \mathrm{~km}$ (Sommer et al., 2014, 2016).

Further, we use wind observations from a collocated meteor radar. The system operates at $32.55 \mathrm{MHz}$ and has a peak power of $30 \mathrm{~kW}$. The radar employs a crossed dipole antenna for transmission and five crossed dipole antennas for recep- 
tion (Jones et al., 1998). The radar detects meteors within a diameter of $600 \mathrm{~km}$. During the summer months we observe between 15000 and 20000 meteors per day. The winds are processed with $30 \mathrm{~min}$ temporal and $1 \mathrm{~km}$ altitude resolution.

Winds presented in this study are computed using a full error propagation of the statistical uncertainties from the radial velocity measurements and are based on a new retrieval technique described in Stober et al. (2017, 2018). These wind estimates have been compared and validated in McCormack et al. (2017) and Wilhelm et al. (2017). Here we describe the key features of the developed wind retrieval algorithm. The starting point of the retrieval is the so-called all-sky fit for both data sets, which can be considered as a more general DBS (Doppler-beam swinging) analysis (Hocking et al., 2001). The advantage of this approach is that we can use an arbitrary number of measurements (at least three) at different positions. We additionally implemented a regularization in time and altitude to retrieve a reliable wind estimate using at least four meteors. The winds are obtained solving the radial wind equation iteratively to ensure a proper error propagation due to the statistical uncertainty of the radial wind velocity measurement and the pointing directions in azimuth and zenith. Typically we need five iterations until we achieve convergence. Typical errors in our obtained winds are of the order of less than $1 \mathrm{~m} \mathrm{~s}^{-1}$ for MAARSY and $1-10 \mathrm{~m} \mathrm{~s}^{-1}$ for the meteor radar. The largest uncertainties occur at the upper and lower boundaries of the observed altitudes.

The multibeam experiments are also appropriate for applying more sophisticated wind analysis methods such as the velocity azimuth display (VAD) (Browning and Wexler, 1968) or the volume velocity processing (VVP) (Waldteufel and Corbin, 1979). If radial velocities are not available for all beam directions due to the patchy PMSE structure, it turns out that the VVP is more suitable and robust (Stober et al., 2013). In addition, the benefit of the VVP technique is to access higher-order kinematic terms such as horizontal divergence, stretching, and shearing deformation in the wind field. As we show in the second part of the paper, VVP allows the decomposition of the wind field into mean winds, mesoscale distortions (e.g., GW with horizontal wavelengths larger than the observation volume), and ripples or wave-like features.

\section{Results}

\subsection{Kelvin-Helmholtz instabilities}

In June 2013, MAARSY was used for a multibeam experiment campaign. During this period, the PMSE strength was rather variable regarding the duration and its horizontal and vertical extension. On 21 June, we observed an interesting PMSE structure with several thin layers showing signs in the morphology, which seem to evolve into KHIs. Figure 3 shows the SNR, the radial velocity, and the spectral width
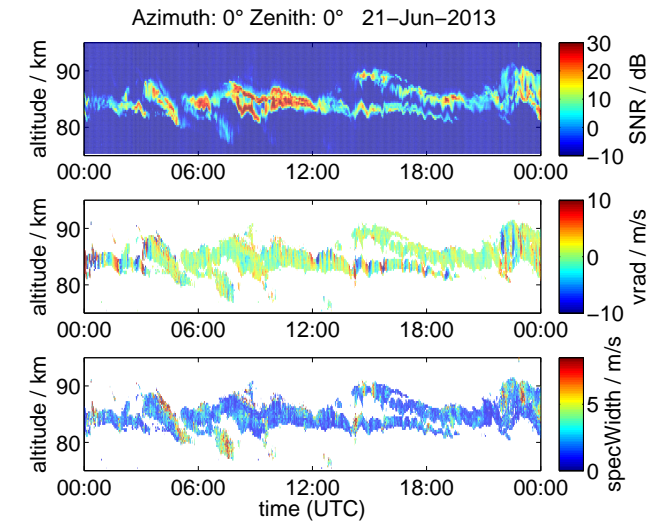

Figure 3. Measured SNR from the vertical beam for 21 June 2013. Radial velocity determined from spectral analysis using a truncated Gaussian fit. Computed spectral width for the vertical beam.

of the vertical beam. There are times when the morphology of the PMSE layer is forced by strong upward and downward motions, which appear in the radial velocity as well. We identify two possible KHI events around 00:30 and around 15:45 UTC. The events are indicated by the morphology of the PMSE showing a strong wave-like up and down modulation followed by a more smeared structure indicating a socalled cat eye pattern. Further, the radial velocity measurements show large amplitude changes within minutes from $\pm 10 \mathrm{~m} \mathrm{~s}^{-1}$.

An advantage of the radar measurements is the Doppler information from which we obtain the 3-D winds independent of the cloud conditions and during daylight. In particular, the stability of the flow can be investigated from the vertical wind shear when the KHIs occur. Meteor radar (MR) data are used to extend the altitude coverage and to complement the MAARSY winds. Figure 4 shows both observations. Both horizontal wind components obtained from MAARSY are shown in Fig. 4a, b. Figure 4c, d present the meteor radar zonal and meridional winds. The zonal and meridional winds are dominated by tides, which typically have amplitudes of $15-25 \mathrm{~m} \mathrm{~s}^{-1}$ (semidiurnal) in the summer mesosphere and the altitude of PMSE (Pokhotelov et al., 2018). Further, the zonal wind reverses at approximately $88 \mathrm{~km}$, separating the westerly mesospheric jet in the lower part from the easterly thermospheric jet above. The wind reversal and the strong semidiurnal tide generate strong wind shears in the flow. Differences in the wind magnitude between both observations are mainly attributed to the different sampling volumes ( $80 \mathrm{~km}$ diameter for MAARSY and $400 \mathrm{~km}$ diameter in the case of the MR) and the temporal resolution (approx. 4 min for MAARSY and $30 \mathrm{~min}$ for the MR winds). The mesoscale wind patterns are in reasonable agreement between both systems.

It is known that KHIs evolve in dynamical unstable flows due to strong shears with $R i=N^{2} / S^{2}<0.25$ 
(a)

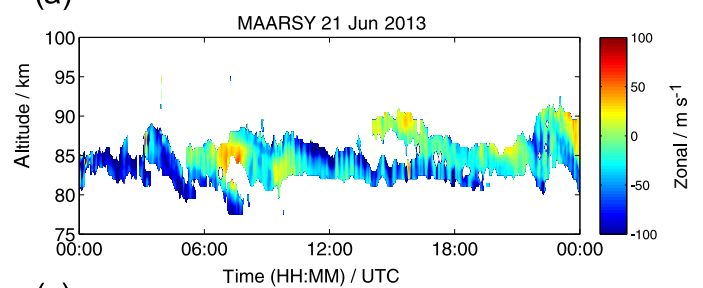

(c)

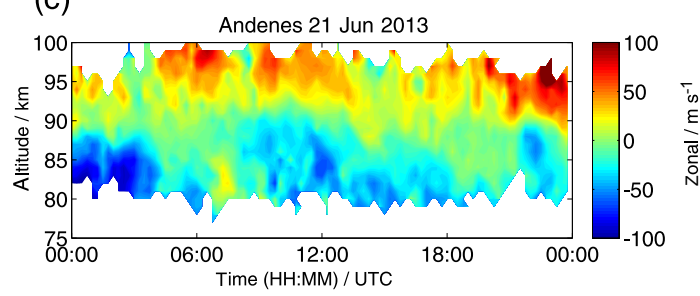

(b)

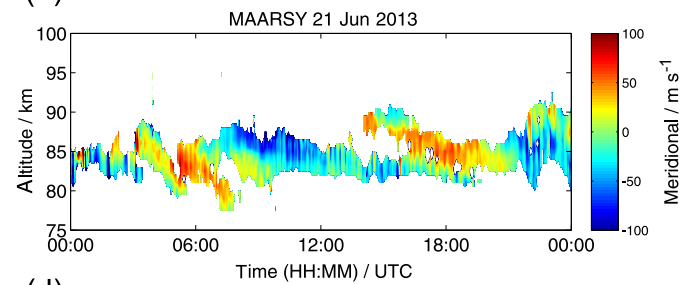

(d)

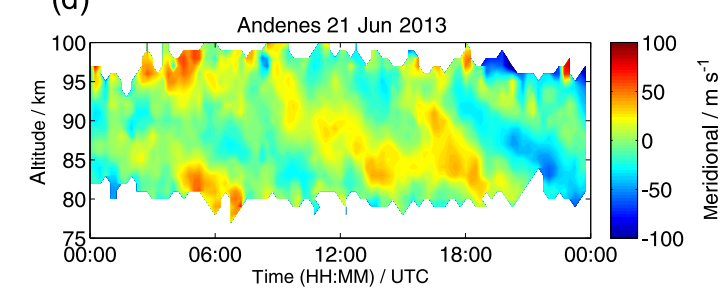

Figure 4. Color-coded zonal and meridional winds for 21 June 2013. Panels (a) and (b) show the observations from MAARSY. Panels (c) and (d) show the data from the collocated meteor radar.

(Miles and Howard, 1964), where $N$ is the Brunt-Väisälä frequency and $S$ describes the horizontal wind shear. The Brunt-Väisälä frequency is computed from

$N=\sqrt{\frac{g}{T}\left(\frac{\mathrm{d} T}{\mathrm{~d} z}+\frac{g}{c_{p}}\right)}$.

Under the assumption of a mesospheric temperature close to the mesopause of $T=130 \mathrm{~K}$, a temperature gradient of $\frac{\mathrm{d} T}{\mathrm{~d} z}=0$, a gravitational acceleration of $g=9.64 \mathrm{~m} \mathrm{~s}^{-2}$, and a specific heat at constant pressure of $c_{p}=1009 \mathrm{~J} \mathrm{~kg}^{-1} \mathrm{~K}^{-1}$, we obtain a Brunt-Väisälä period of approximately $4 \mathrm{~min}$ at the altitude of the PMSE. We also estimated the BruntVäisälä period above and below the PMSE layer using a NRLMSISE-00 profile (Picone et al., 2002).

The obtained $R i$ numbers are shown in Fig. 5 assuming a NRLMSISE-00 background temperature profile shifted to match $130 \mathrm{~K}$ at the mesopause. The upper panel shows the $R i$ obtained from MAARSY and the lower panel shows the MR-derived results. In particular, the MAARSY data show that there are often low $R i$ numbers within the PMSE layer, which is expected considering that turbulence is an important factor in the formation of PMSE (Rapp and Lübken, 2004). Similarly, $R i$ numbers are obtained from the MR, although the coarser vertical resolution as well as the vertical averaging in the wind analysis have to be taken into account to estimate the Ri. Our wind measurements confirm that KHI occurred during times showing a strong vertical wind shear in the horizontal wind speeds that could have generated a sufficiently small $R i<0.25$, supporting the notion that the instabilities are of a dynamical origin. However, as we use an empirical temperature background profile, the low $R i$ values indicate in first place a strong vertical wind shear instead of absolute measurements of $R i$.

The wave characteristics are derived applying a Stokes analysis (Vincent and Fritts, 1987; Lue et al., 2013). In a first
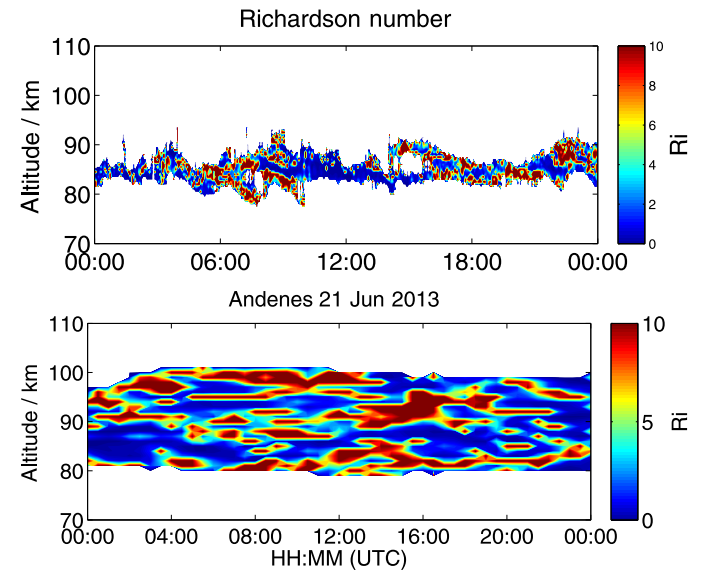

Figure 5. Richardson number estimated from the vertical wind shear and Brunt-Väisälä frequency. The Richardson numbers were calculated from the vertical wind shear and the Brunt-Väisälä frequency assuming a NRLMSISE-00 background temperature profile shifted by $10 \mathrm{~K}$ to lower temperatures.

step, we computed the wavelet spectra for all three components (Torrence and Compo, 1998). Figure 6 shows the resulting spectra for the zonal and meridional wind component after the subtraction of the mean wind and the tidal components. Figure $6 \mathrm{a}, \mathrm{b}$ indicate two wave bursts with periods $T<30 \mathrm{~min}$, which coincide with the occurrence times of a strong wave-like modulation of the morphology of the SNR (see Fig. 3). For the first KHI event, we observed a mean period of $11.5 \pm 1.5 \mathrm{~min}$ in all three wind components (zonal, meridional, and vertical) between 00:00 and 00:50 UTC. The second KHI occurred between 15:00 and 16:00 UTC and had a mean observed period of $20.3 \pm 1.0 \mathrm{~min}$ in all three wind components. However, the wavelet spectra shown in Fig. 6 

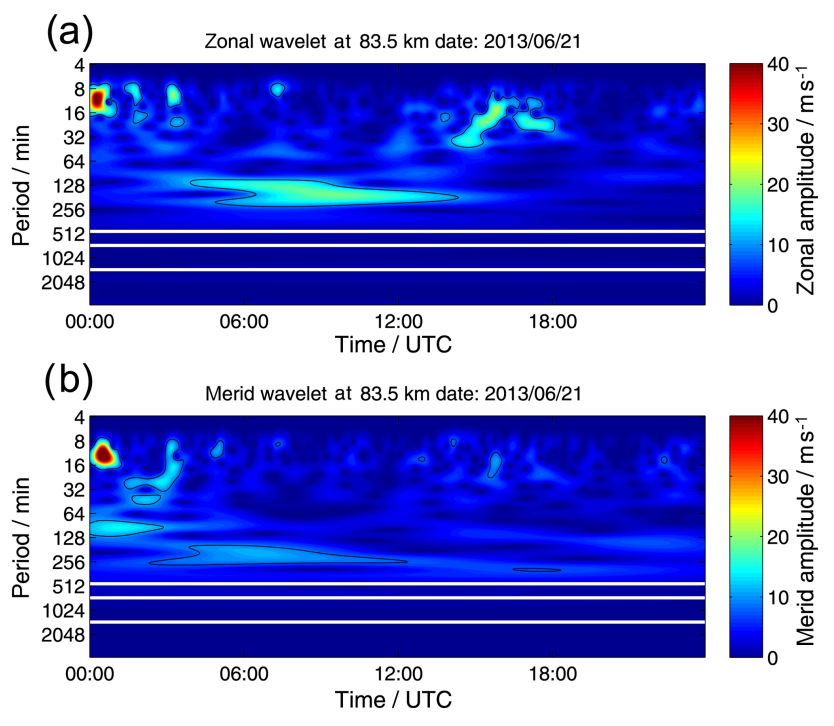

Figure 6. Wavelet spectra of the zonal and meridional wind using the MAARSY wind measurements after the diurnal, semidiurnal, and terdiurnal tide was removed.

also indicates some spread in the observed periods, suggesting some dispersion between the events.

The mean horizontal wavelength of the first group of KHIs was determined to be $\lambda_{\mathrm{h}}=10.7 \pm 5 \mathrm{~km}$ and for the second event we estimated a wavelength of $\lambda_{\mathrm{h}}=12.3 \pm 5.3 \mathrm{~km}$. These values are obtained assuming that the KHIs are advected by the mean winds through the radar beam. The vertical extension of the $\mathrm{KH}$ billows is estimated from our range time insensitivity (RTI) to be $\lambda_{z}=3 \pm 0.5 \mathrm{~km}$. Fritts et al. (2014) conducted direct numerical simulations (DNSs) to characterize the KHI evolution at the MLT and investigated the evolution of $\mathrm{KHI}$ in the presence of the mean shear flows and GW-induced shear flows for small $R i=0.05-0.20$. The DNSs are compared to actual NLC observations (Baumgarten and Fritts, 2014). This leads to a depth-to-wavelength ratio of $0.3-0.4$, suggesting a small initial $R i$ (Werne and Fritts, 1999, 2001).

In Fig. 7, we zoom in on the SNR, the vertical velocity, and the spectral width for both KHIs. The SNR indicates a train of ripples (first KHI event) and a single wave-like event for the second KHI passing through the vertical beam. Such structures are rather common in airglow images (Hecht et al., 2005, 2007). Depending on the temporal evolution of the KHI, we observe strong vertical motions as visualized in Fig. 7c and d. Considering PMSE as an inert tracer, the layer follows the upward and downward motion of the propagating billows. After the passage of the KHIs, the layer appears to be smoother and vertically smeared compared to the more confined structure that existed before, which is likely related to the turbulence generated by the KHIs. From our spectral width measurement in Fig. 7e and f, we obtained that the vertical motion of the KHIs is accompanied by an increased spectral width, which is associated with an increased turbulence generation.

We further identified the presence of some GWs that become unstable and likely generated the ripple structures. In Fig. 8 we present the zonal and meridional wavelet spectra for three altitudes at 83,90 , and $95 \mathrm{~km}$. The wavelet spectra show the MR wind after removing the tides and mean flow. The pictures point out that there are some components with GW-like periods with significant amplitudes at $83 \mathrm{~km}$ altitude, which more or less disappear at $90 \mathrm{~km}$ and then grow again. This is in particular obvious for the zonal wind component and to a smaller degree for the meridional wind.

\subsection{Gravity wave statistics using horizontally resolved radial velocities}

In the previous section, we presented results of ripples and/or billows causing modulations in rather thin PMSE layers. However, there are times when PMSE covers a much larger vertical and horizontal volume. Sometimes the complete scanning area shown in Fig. 1 was filled with PMSE and provided a sufficiently strong backscatter signal to obtain reliable radial velocity measurements for each beam direction. This permits the construction of radial velocity maps of the horizontal wind variability caused by ripples or GWs propagating through the layer.

Horizontally resolved radial velocity maps using PMSE as a passive tracer for neutral dynamics were already introduced by Stober et al. (2013). Here, we apply this method to enhance our statistics, investigating several days of our multibeam observations from 21 to 30 June 2013. Considering our previous experience retrieving monochromatic GW properties from horizontally resolved radial velocity images, we modified the experiment to ensure that our sampling time (time for a complete scan) is faster than the Brunt-Väisälä period for the summer mesopause, which is around $4 \mathrm{~min}$. Further, we improved our analysis to fit directly for the horizontal wavelength, propagation direction, and phase speed.

Before we can extract ripple or GW features from our radial velocity measurements, we need to remove the mean wind and large-scale distortions or contributions from waves with scales larger than our observation volume. Therefore, we fit for the wind field using the VVP approach (Browning and Wexler, 1968; Waldteufel and Corbin, 1979). The basic idea is to drop the assumption that the wind field has to be homogenous within the observation volume. Browning and Wexler (1968) expressed the wind field by a Taylor series,

$u=u_{0}+\frac{\partial u}{\partial x}\left(x-x_{0}\right)+\frac{\partial u}{\partial y}\left(y-y_{0}\right)$
$v=v_{0}+\frac{\partial v}{\partial x}\left(x-x_{0}\right)+\frac{\partial v}{\partial y}\left(y-y_{0}\right)$.

Here, $u_{0}$ and $v_{0}$ express the mean zonal and meridional wind in the observed volume, respectively, and $\partial u / \partial x, \partial u / \partial y$ and $\partial v / \partial x, \partial v / \partial y$ express a zonal and meridional wind gradient 

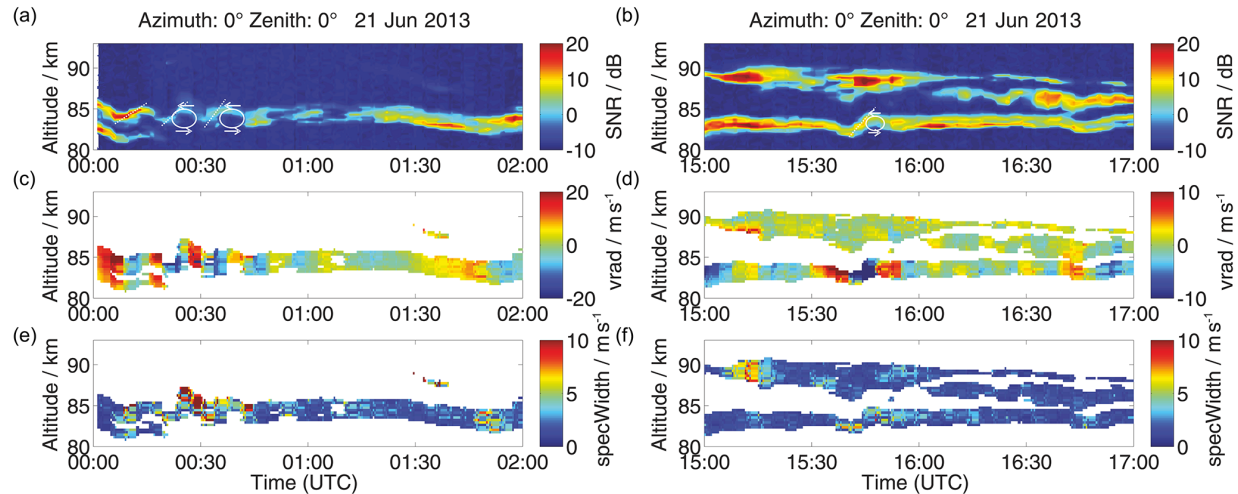

Figure 7. Zoom in on the SNR (a, b), radial velocity $(\mathbf{c}, \mathbf{d})$, and spectral width $(\mathbf{e}, \mathbf{f})$ for the two Kelvin-Helmholtz instabilities observed on 21 June 2013.
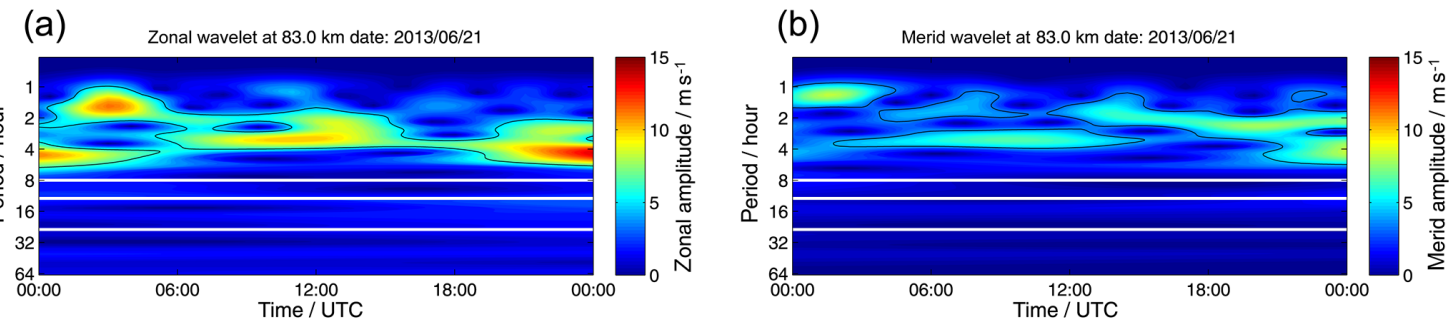

(c)

(d)
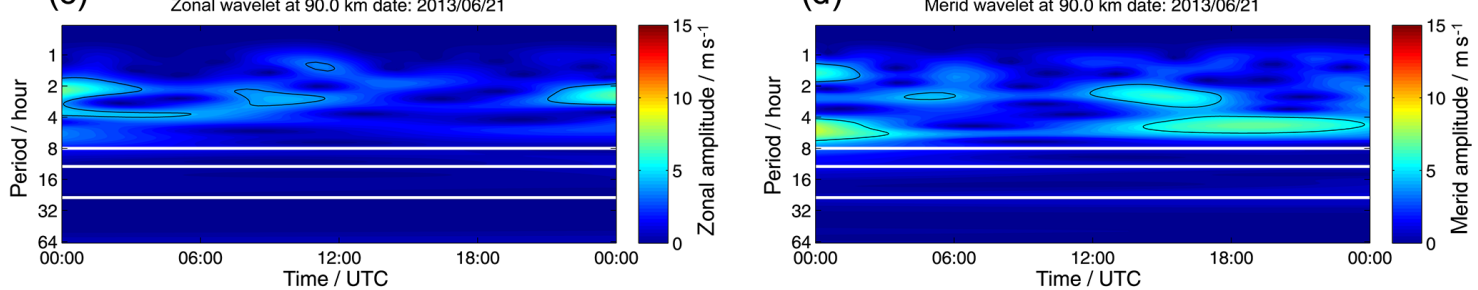

(e)
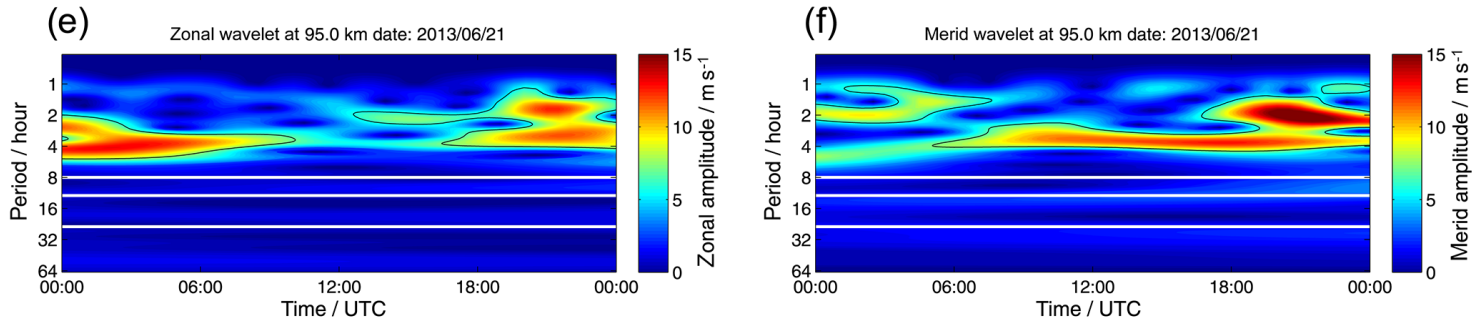

Figure 8. (a-f) Zonal and meridional amplitude wavelet spectra for different altitudes. The time series were filtered to remove the mean wind as well as the tidal components. The white lines indicate the periods of the diurnal, semidiurnal, and terdiurnal tide.

in the $x$ and $y$ directions. For simplicity, we assume that the radar is located at $x_{0}=0$ and $y_{0}=0$. Although the first-order approach outlined here does not account for all the variability within the observation volume, it provides a good approximation of the mesoscale situation. The first-order zonal and meridional gradient terms in the $x$ and $y$ directions can be associated with waves and inhomogeneities larger than the observation volume.

We use the first-order wind approximation given above to retrieve smaller structures within our field of view. We de- compose each radial velocity measurement by subtracting the VVP solution to obtain a radial velocity residual $v_{\mathrm{r}}^{\text {res }}$ for each beam,

$v_{\mathrm{r}}^{\mathrm{res}}=v_{\mathrm{r}}^{\mathrm{obs}}-v_{\mathrm{r}}^{\mathrm{VVP}}$.

Here, $v_{\mathrm{r}}^{\mathrm{obs}}$ is the individually observed radial velocity for each beam. In fact, the radial velocity residuum now includes the wind variability smaller than the observation volume.

A sequence of nine successive radial velocity images containing all different beam directions is shown in Fig. 9. The 

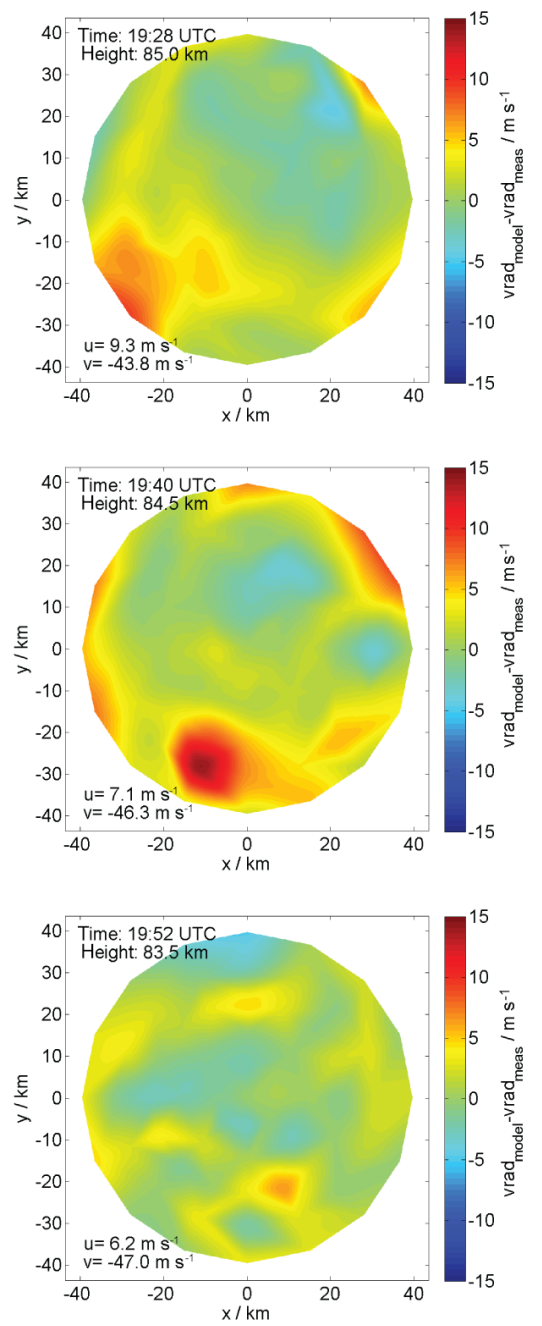
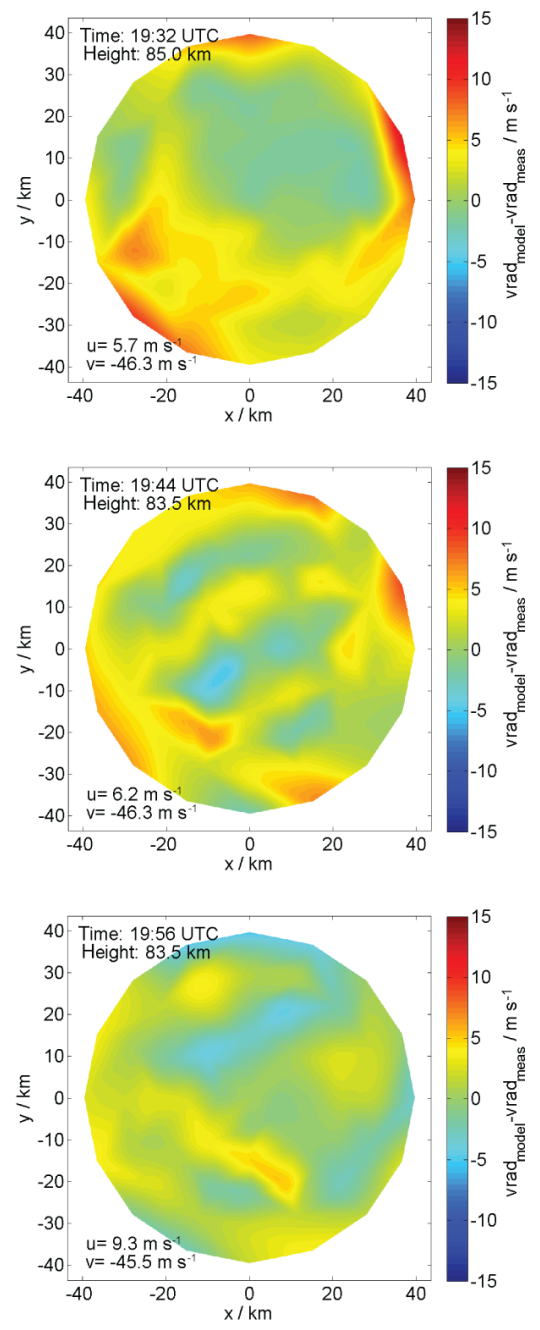
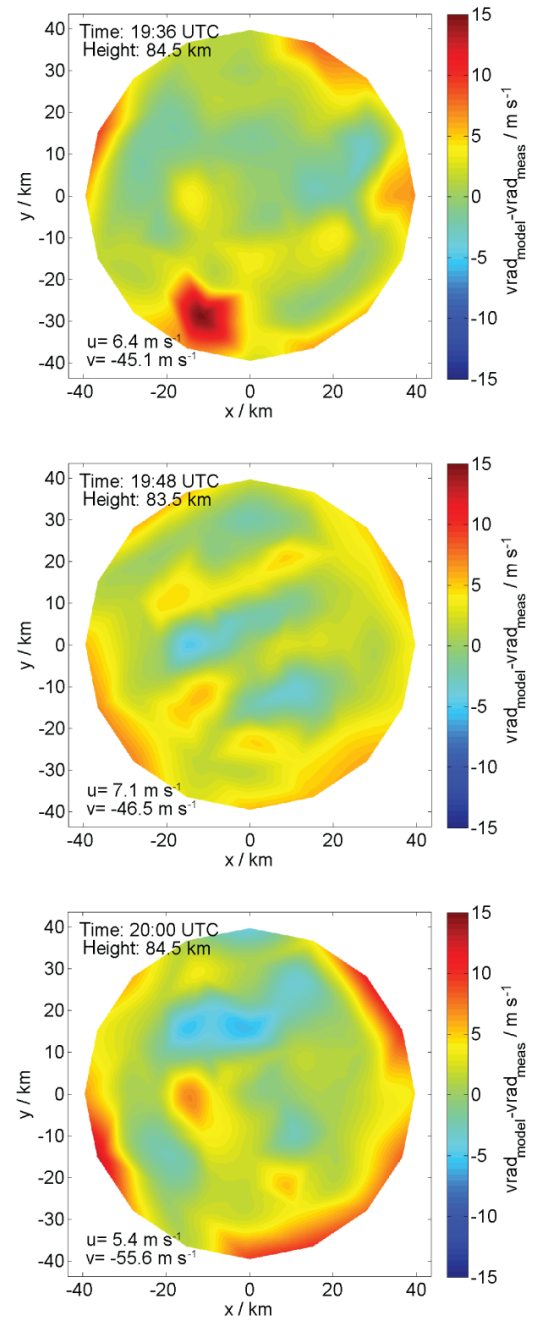

Figure 9. Sequence of nine successive radial velocity residual images measured on 30 June 2013.

measurements were taken on 30 June 2013 and are representative for the type of features that can be seen in these images. Some frames show rather coherent and wave-like features; other images seem to be more dominated by random structures, which may be caused by the superposition of several waves or ripples moving through our field of view. Whenever we found a coherent wave-like structure in these images (by looking at the images) that lasted at least three successive frames, we tried to fit the wave features, i.e., horizontal wavelength, phase speed, and propagation direction.

Following Fritts and Alexander (2003), a GW is described in the linear theory by

$(u, v, w)=\left(u^{\prime}, v^{\prime}, w^{\prime}\right) \cdot e^{i(k x+l y+m z-\omega t)+\frac{z}{2 H}}$.

Here, $u^{\prime}, v^{\prime}$, and $w^{\prime}$ are the zonal, meridional, and vertical amplitude of the GW, respectively; $k$ and $l$ are the zonal and meridional horizontal wave numbers; $m$ denotes the vertical wave number; $\omega$ is the Eulerian GW frequency; and $H$ is the scale height. As we just observe the horizontal structure of the wave, we modify Eq. (4) by introducing a phase $\varphi=$ $m z-\omega t$. Further, we can neglect the term for the amplitude growth with altitude, $\frac{z}{2 H}$, as we only have information about the wave at a fixed altitude. Thus, we can rewrite Eq. (4),

$(u, v, w)=\left(u^{\prime}, v^{\prime}, w^{\prime}\right) \cdot e^{i(k x+l y+\varphi)}$.

Assuming only a slow change of the intrinsic frequency and vertical wavelength over successive frames, we infer the vertical wave number $m$ and the frequency $\omega$ using the time derivative of the phase $\varphi$,

$\frac{\mathrm{d} \varphi}{\mathrm{d} t}=-\omega$.

The advantage of the outlined procedure is that we directly obtain the intrinsic wave or ripple characteristics. The intrinsic wave frequency $\hat{\omega}$ is straightforwardly computed as we know the horizontal wavelength, the propagation direction, and the mean mesoscale wind components. The intrinsic fre- 


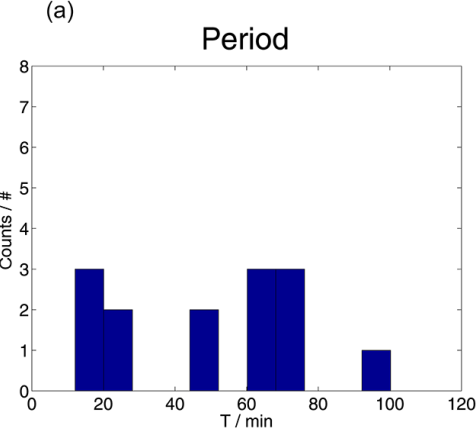

(d)

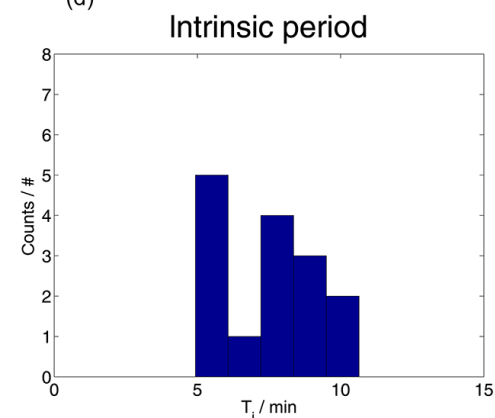

(b)

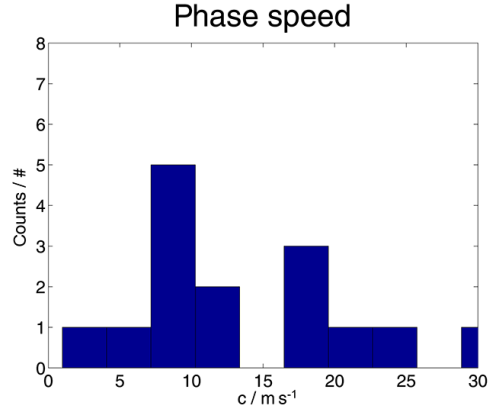

(e)

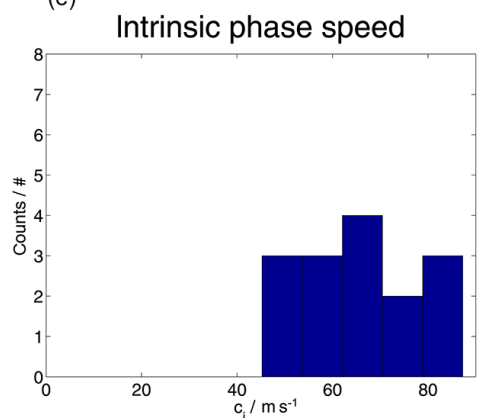

(c)

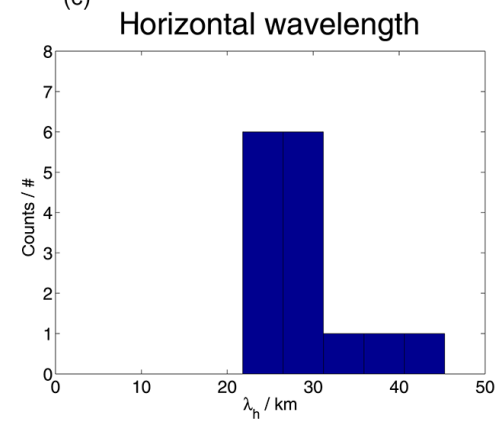

(f)

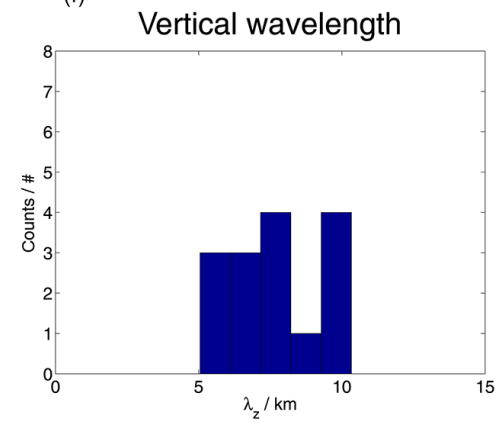

Figure 10. (a) Histogram of the observed GW periods. (b) Histogram of the determined phase speeds using the 2-D fit. (c) Obtained horizontal wavelengths. (d) Histogram of derived intrinsic GW periods. (e) Statistics of the computed intrinsic phase speeds. (f) Histogram of estimated vertical wavelengths assuming linear theory.

quency and phase speed $\hat{c}$ are given by the Doppler relation;

$\hat{\omega}=\omega-\vec{k} \cdot \vec{u}$,

$\hat{c}=c-u$.

In total, we were able to identify 15 ripple events within the 9-day campaign. For that, we searched all 2-D radial velocity images for coherent wave-like features that lasted at least three successive frames. The obtained parameters of these ripples are presented in Fig. 10 with regard to the (intrinsic) period, the (intrinsic) phase speed, and the horizontal and vertical wavelength. The duration of the GWs or ripples within the scanning volume varied between 10 and $50 \mathrm{~min}$. Most of the events lasted approximately 20-25 min, viz. for more than four frames. We did not obtain intrinsic periods shorter than the Brunt-Väisälä period, but they are already rather close to this limit. It is remarkable that the computed periods are much larger with $20-90 \mathrm{~min}$, as most of these waves or ripples move against the background mesoscale flow. This behavior also appears in the intrinsic and observed phase speeds. Intrinsic phase speeds had values between 50 and $90 \mathrm{~m} \mathrm{~s}^{-1}$, whereas the observed phase speeds have values between 2 and $23 \mathrm{~m} \mathrm{~s}^{-1}$. At phase speeds faster than $60 \mathrm{~m} \mathrm{~s}^{-1}$ the wave-like structures would travel more than the diameter of the radar beam, and hence the positive and negative phase fronts would cancel each other out. Due to the size of the scanning volume and the subtraction of the mesoscale variability, the horizontal wavelengths represent the characteris- tic scale of our scanning volume between 20 and $40 \mathrm{~km}$. The obtained vertical wavelengths are rather short, with values ranging from 5 to $10 \mathrm{~km}$.

The polar diagram in Fig. 11 shows the distribution of the propagation direction for all 15 events. For simplicity, we just indicated the mean wind direction with a red arrow. However, individual ripples moved at a certain angle to the prevailing winds. These angles between the prevailing wind and the propagation direction of the wave or ripple showed values between 90 and $180^{\circ}$.

\section{Discussion}

Analyzing the wind structure from MAARSY as well as the MR wind observations, we showed that the observed modulations in the morphology of PMSE are likely caused by dynamical instability. This is supported by the computed Richardson number $R i<0.25$, which is related to a strong shear flow. Further, we are able to show that there are mesoscale GWs present during the observation of the KHI. These mesoscale GWs show significant amplitudes at the height of the KHI, a much smaller amplitude $5 \mathrm{~km}$ above, and an increased amplitude at $95 \mathrm{~km}$ altitude. According to Lindzen (1988), upward-propagating waves do not dissipate their whole energy at once. They dissipate some energy, decreasing the GW amplitude, and start growing again above, which is well represented in the MR data. 


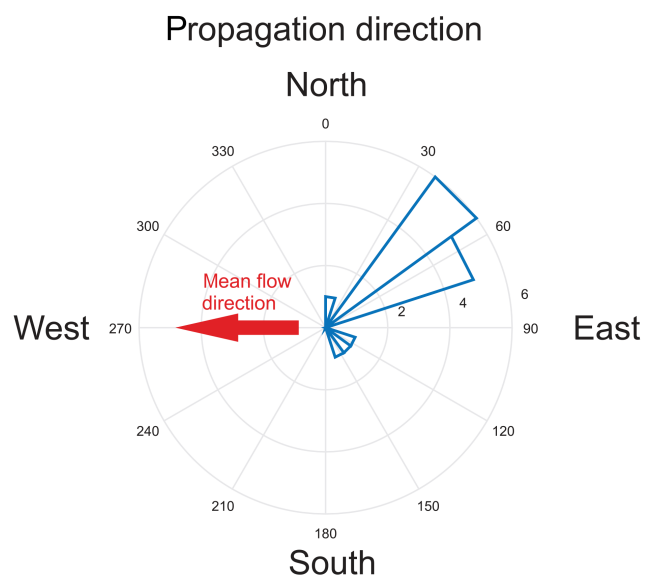

Figure 11. Polar diagram of GWs and ripple propagation direction. The red arrow denotes the mean wind direction.

Other observations above Andenes suggest that KHIs seem to occur frequently at the polar MLT. Fritts et al. (2014) and Baumgarten and Fritts (2014) analyzed two KHI events from a NLC camera network and inferred the background wind situation by tracing the ice clouds over a much larger field of view than the billows. They retrieved a horizontal wavelength of $20-30 \mathrm{~km}$ for the generating of GWs. Baumgarten and Fritts (2014) investigated different events and derived horizontal scales of 5-10 km for the KHI, which are in remarkable agreement to our measurements of 7-12 km. Due to the weather conditions (clouds in the troposphere) there are no data available to perform a direct comparison with our data. Comparable horizonal and vertical wavelengths are also reported from midlatitude GRIPS (Ground-based Infrared Pbranch Spectrometer) measurements (Wüst et al., 2017).

Comparing our results to previous optical observations from a NLC camera at Trondheim monitoring the MLT above Andenes suggests slightly higher observed phase speeds and much shorter observed wave periods (Demissie et al., 2014). The horizontal wavelengths are comparable and had values between 20 and $40 \mathrm{~km}$. However, these measurements were taken between summer 2007 and summer 2011 and do not cover the period presented in this paper.

Our observations are also consistent with what was reported previously from airglow observations, although these measurements were not taken at the same location. Hecht et al. (2005) showed that breaking mesoscale GWs form ripple structures that evolve into KHIs. Hecht et al. (2007) derived some statistics of ripples and investigated whether they were of dynamical or convective origin. They inferred the atmospheric stability from lidar and MR winds. The described features are similar to what we observed with MAARSY.

Comparing our statistical results with the model data from Horinouchi et al. (2002) provides further indication that we have observed dynamically unstable KHI. Their model resolved convectively generated mesoscale GWs that propa- gate up to the mesosphere. Once the GWs reach the mesosphere they become dynamically instable and form the ripple features. They obtained a typical billow scale of $8-15 \mathrm{~km}$ that occupies a region with $30-50 \mathrm{~km}$ in diameter. The model shows that such events last about 25-40 min. Considering our observations, we likely observed similar scales and durations, which reassure us that most of the observed events are dynamically instable KHI. However, we cannot absolutely rule out the possibility that some of the wave-like features were of convective origin. Such secondary instabilities can occur after KHIs (Hecht et al., 2005).

Further, we have to point out that in the model from Horinouchi et al. (2002) the source of the mesoscale GWs is convective clouds. This is likely not the case at Andenes. We assume that tropospheric jet instabilities are the more likely source of mesoscale GWs at polar latitudes. A detailed discussion about the wave sources is beyond the scope of this paper and requires dedicated model runs.

\section{Conclusions}

In this study we present unique observations of ripples and $\mathrm{KHI}$ in the wind field during full daylight conditions at polar latitudes above Andenes. The observations were conducted with MAARSY during summer 2013 using PMSE as a tracer for neutral dynamics. The wind analysis was complemented with data from a collocated MR in order to infer and validate the mesoscale GW activity.

We were able to identify two KHIs from the morphology of the PMSE layer and estimated the characteristic scale of these billows to be of the order of $8-12 \mathrm{~km}$. Our measurements indicate an increased spectral width accompanied with an increased turbulence while the billows occurred in the vertical beam. In addition, we inferred from the MR observations the presence of mesoscale GWs that dissipated a part of their energy between 83 and $90 \mathrm{~km}$ altitude and an amplitude growth above, which is at least in qualitative agreement with Lindzen (1988). More recent modeling results from Hickey et al. (1998) and Fritts et al. (2015) with comprehensive models also show qualitative agreements with our observations. These results suggest that GW wave packets may undergo a significant acceleration in their phase speeds when propagating upward, reaching different background flows and evolving into different forms of instabilities. Other mesospheric observations already indicated that secondary wave generation due to wave ducting can lead to waves propagating with rather high phase speeds (Snively and Pasko, 2003).

Further, we demonstrated that multibeam experiments are suitable to directly obtain ripple properties such as horizontal wavelength, intrinsic frequency, and propagation direction. The observed values are in reasonable agreement with model simulations of breaking mesoscale GWs generated from convective tropospheric clouds (Horinouchi et al., 2002) and are 
also consistent with airglow observations (Hecht et al., 2005, 2007).

Data availability. The data are available upon request to stober@iap-kborn.de.

Competing interests. The authors declare that they have no conflict of interest.

Special issue statement. This article is part of the special issue "Sources, propagation, dissipation and impact of gravity waves (ACP/AMT inter-journal SI)". It is not associated with a conference.

Acknowledgements. We thank the IAP technical staff for keeping MAARSY operational. The helpful discussions about gravity waves with Peter Hoffmann are acknowledged. This work was partially supported by the WATILA project (SAW-2015-IAP-1). Svenja Sommer was funded by ILWAO (SAW-2012-IAP-4). MAARSY was built under grant 01LP0802A of the German Federal Ministry of Education and Research. Some of the contributing researchers are supported by the German research grant MATMELT (SAW-2014-IAP-1). Carsten Schult was supported by grant STO 1053/1-1 (AHEAD) of the Deutsche Forschungsgemeinschaft (DFG).

Edited by: Markus Rapp

Reviewed by: two anonymous referees

\section{References}

Baumgarten, G. and Fritts, D. C.: Quantifying Kelvin-Helmholtz instability dynamics observed in noctilucent clouds: 1 . Methods and observations, J. Geophys. Res.-Atmos., 119, 9324-9337, https://doi.org/10.1002/2014JD021832, 2014.

Browning, K. and Wexler, R.: The Determination of Kinematic Properties of a Wind field Using Doppler Radar, J. App. Meteorol., 7, 105-113, 1968.

Chau, J. L. and Kudeki, E.: First E- and D-region incoherent scatter spectra observed over Jicamarca, Ann. Geophys., 24, 12951303, https://doi.org/10.5194/angeo-24-1295-2006, 2006.

Chilson, P. B., Yu, T.-Y., Palmer, R. D., and Kirkwood, S.: Aspect sensitivity measurements of polar mesosphere summer echoes using coherent radar imaging, Ann. Geophys., 20, 213-223, https://doi.org/10.5194/angeo-20-213-2002, 2002.

Demissie, T. D., Espy, P. J., Kleinknecht, N. H., Hatlen, M., Kaifler, N., and Baumgarten, G.: Characteristics and sources of gravity waves observed in noctilucent cloud over Norway, Atmos. Chem. Phys., 14, 12133-12142, https://doi.org/10.5194/acp-14-121332014, 2014.

Fritts, D. and Alexander, M. J.: Gravity wave dynamics and effects in the middle atmosphere, Rev. Geophys., 41, 1-64, https://doi.org/10.1029/2001RG000106, 2003.
Fritts, D. C., Baumgarten, G., Wan, K., Werne, J., and Lund, T.: Quantifying Kelvin-Helmholtz instability dynamics observed in noctilucent clouds: 2. Modeling and interpretation of observations, J. Geophys. Res.-Atmos., 119, 9359-9375, https://doi.org/10.1002/2014JD021833, 2014.

Fritts, D. C., Laughman, B., Lund, T. S., and Snively, J. B.: Self acceleration and instability of gravity wave packets: 1 . Effects of temporal localization, J. Geophys. Res.-Atmos., 120, 87838803, https://doi.org/10.1002/2015JD023363, 2015.

Fukao, S., Luce, H., Mega, T., and Yamamoto, M. K.: Extensive studies of large-amplitude Kelvin-Helmholtz billows in the lower atmosphere with VHF middle and upper atmosphere radar, Q. J. Roy. Meteor. Soc., 137, 1019-1041, 2011.

Hecht, J. H., Fricke-Begemann, C., Walterscheid, R. L., and Höffner, J.: Observations of the breakdown of an atmospheric gravity wave near the cold summer mesopause at $54 \mathrm{~N}$, Geophys. Res. Lett., 27, 879-882, https://doi.org/10.1029/1999GL010792, 2000.

Hecht, J. H., Liu, A. Z., Walterscheid, R. L., and Rudy, R. J.: Maui Mesosphere and Lower Thermosphere (Maui MALT) observations of the evolution of Kelvin-Helmholtz billows formed near $86 \mathrm{~km}$ altitude, J. Geophys. Res.-Atmos., 110, D09S10, https://doi.org/10.1029/2003JD003908, 2005.

Hecht, J. H., Liu, A. Z., Walterscheid, R. L., Franke, S. J., Rudy, R. J., Taylor, M. J., and Pautet, P.-D.: Characteristics of shortperiod wavelike features near $87 \mathrm{~km}$ altitude from airglow and lidar observations over Maui, J. Geophys. Res.-Atmos., 112, D16101, https://doi.org/10.1029/2006JD008148, 2007.

Hickey, M. P., Taylor, M. J., Gardner, C. S., and Gibbons, C. R.: Full wave modeling of small scale gravity waves using Airborne Lidar and Observations of the Hawaiian Airglow (ALOHA 93) $\mathrm{O}(1 \mathrm{~S})$ images and coincident $\mathrm{Na}$ wind/temperature lidar measurements, J. Geophys. Res.-Atmos., 103, 6439-6453, https://doi.org/10.1029/97JD03373, 1998.

Hocking, W., Fuller, B., and Vandepeer, B.: Real-time determination of meteor-related parameters utilizing modern digital technology, J. Atmos. Sol.-Terr. Phy., 63, 155-169, https://doi.org/10.1016/S1364-6826(00)00138-3, 2001.

Horinouchi, T., Nakamura, T., and Kosaka, J.-I.: Convectively generated mesoscale gravity waves simulated throughout the middle atmosphere, Geophys. Res. Lett., 29, 3-1-3-4, https://doi.org/10.1029/2002GL016069, 2002.

Jones, J., Webster, A. R., and Hocking, W. K.: An improved interferometer design for use with meteor radars, Radio Sci., 33, 55-65, https://doi.org/10.1029/97RS03050, 1998.

Klostermeyer, J. and Rüster, R.: Radar observation and model computation of a jet stream-generated Kelvin-Helmholtz instability, J. Geophys. Res.-Oceans, 85, 2841-2846, https://doi.org/10.1029/JC085iC05p02841, 1980.

Klostermeyer, J. and Rüster, R.: Further study of a jet stream-generated Kelvin-Helmholtz instability, J. Geophys. Res.-Oceans, 86, 6631-6637, https://doi.org/10.1029/JC086iC07p06631, 1981.

Kudeki, E., Bhattacharyya, S., and Woodman, R. F.: A new approach in incoherent scatter $\mathrm{F}$ region $\mathrm{E} \times \mathrm{B}$ drift measurements at Jicamarca, J. Geophys. Res.-Space, 104, 28145-28162, https://doi.org/10.1029/1998JA900110, 1999. 
Latteck, R. and Bremer, J.: Long-term changes of polar mesosphere summer echoes at $69^{\circ} \mathrm{N}$, J. Geophys. Res.-Atmos., 118, 1044110448, https://doi.org/10.1002/jgrd.50787, 2012.

Latteck, R., Singer, W., Rapp, M., Vandepeer, B., Renkwitz, T., Zecha, M., and Stober, G.: MAARSY: The new MST radar on Andøya - System description and first results, Radio Sci., 47, RS1006, https://doi.org/10.1029/2011RS004775, 2012.

Lehmacher, G., Guo, L., Kudeki, E., Reyes, P., Akgiray, A., and Chau, J.: High-resolution observations of mesospheric layers with the Jicamarca VHF radar, Adv. Space Res., 40, 734-743, 2007.

Lehmacher, G. A., Kudeki, E., Akgiray, A., Guo, L., Reyes, P., and Chau, J.: Radar cross sections for mesospheric echoes at Jicamarca, Ann. Geophys., 27, 2675-2684, https://doi.org/10.5194/angeo-27-2675-2009, 2009.

Lindzen, R. S.: Supersaturation of Vertically Propagating Internal Gravity Waves, J. Atmos. Sci., 45, 705-711, 1988.

Lue, H. Y., Kuo, F. S., Fukao, S., and Nakamura, T.: Studies of gravity wave propagation in the mesosphere observed by MU radar, Ann. Geophys., 31, 845-858, https://doi.org/10.5194/angeo-31845-2013, 2013.

McCormack, J., Hoppel, K., Kuhl, D., de Wit, R., Stober, G., Espy, P., Baker, N., Brown, P., Fritts, D., Jacobi, C., Janches, D., Mitchell, N., Ruston, B., Swadley, S., Viner, K., Whitcomb, T., and Hibbins, R.: Comparison of mesospheric winds from a high-altitude meteorological analysis system and meteor radar observations during the boreal winters of 20092010 and 2012-2013, J. Atmos. Sol.-Terr. Phy., 154, 132-166, https://doi.org/10.1016/j.jastp.2016.12.007, 2017.

Miles, J. W. and Howard, L. N.: Note on a heterogeneous shear flow, J. Fluid Mech., 20, 331-336, https://doi.org/10.1017/S0022112064001252, 1964.

Picone, J. M., Hedin, A. E., Drob, D. P., and Aikin, A. C.: NRLMSISE-00 empirical model of the atmosphere: Statistical comparisons and scientific issues, J. Geophys. Res.-Space, 107, 1468, https://doi.org/10.1029/2002JA009430, 2002.

Pokhotelov, D., Becker, E., Stober, G., and Chau, J. L.: Seasonal variability of atmospheric tides in the mesosphere and lower thermosphere: meteor radar data and simulations, Ann. Geophys. Discuss., https://doi.org/10.5194/angeo-2018-17, in review, 2018.

Rapp, M. and Lübken, F.-J.: Polar mesosphere summer echoes (PMSE): Review of observations and current understanding, Atmos. Chem. Phys., 4, 2601-2633, https://doi.org/10.5194/acp-42601-2004, 2004.

Reid, I. M., Ruester, R., and Schmidt, G.: VHF radar observations of cat's-eye-like structures at mesospheric heights, Nature, 327, 43-45, https://doi.org/10.1038/327043a0, 1987.

Sheth, R., Kudeki, E., Lehmacher, G., Sarango, M., Woodman, R., Chau, J., Guo, L., and Reyes, P.: A high-resolution study of mesospheric fine structure with the Jicamarca MST radar, Ann. Geophys., 24, 1281-1293, https://doi.org/10.5194/angeo24-1281-2006, 2006.

Snively, J. B. and Pasko, V. P.: Breaking of thunderstorm generated gravity waves as a source of short period ducted waves at mesopause altitudes, Geophys. Res. Lett., 30, 2254, https://doi.org/10.1029/2003GL018436, 2003.
Sommer, S., Stober, G., Chau, J. L., and Latteck, R.: Geometric considerations of polar mesospheric summer echoes in tilted beams using coherent radar imaging, Adv. Radio Sci., 12, 197-203, https://doi.org/10.5194/ars-12-197-2014, 2014.

Sommer, S., Stober, G., and Chau, J. L.: On the angular dependence and scattering model of polar mesospheric summer echoes at VHF, J. Geophys. Res.-Atmos., 121, 278-288, https://doi.org/10.1002/2015JD023518, 2016.

Stober, G., Sommer, S., Rapp, M., and Latteck, R.: Investigation of gravity waves using horizontally resolved radial velocity measurements, Atmos. Meas. Tech., 6, 2893-2905, https://doi.org/10.5194/amt-6-2893-2013, 2013.

Stober, G., Matthias, V., Jacobi, C., Wilhelm, S., Höffner, J., and Chau, J. L.: Exceptionally strong summer-like zonal wind reversal in the upper mesosphere during winter 2015/16, Ann. Geophys., 35, 711-720, https://doi.org/10.5194/angeo-35-711-2017, 2017.

Stober, G., Chau, J. L., Vierinen, J., Jacobi, C., and Wilhelm, S.: Retrieving horizontally resolved wind fields using multistatic meteor radar observations, Atmos. Meas. Tech. Discuss., https://doi.org/10.5194/amt-2018-93, in review, 2018.

Suzuki, S., Shiokawa, K., Otsuka, Y., Kawamura, S., and Murayama, Y.: Evidence of gravity wave ducting in the mesopause region from airglow network observations, Geophys. Res. Lett., 40, 601-605, https://doi.org/10.1029/2012GL054605, 2013.

Taylor, M. J., Pendleton Jr, W. R., Pautet, P.-D., Zhao, Y., Olsen, C., Babu, H. K. S., Medeiros, A. F., and Takahashi, H.: Recent progress in mesospheric gravity wave studies using nigthglow imaging system, Revista Brasileira de Geofisica, 25, 49-58, 2007.

Torrence, C. and Compo, G. P.: A Practical Guide to Wavelet Analysis, B. Am. Meteorol. Soc., 79, 61-78, 1998.

Vincent, R. A. and Fritts, D. C.: A climatology of gravity wave motions in the mesopause region at Adelaide, Australia, J. Atmos. Sci., 44, 748-760, 1987.

Waldteufel, P. and Corbin, H.: On the Analysis of Single-Doppler Radar Data, J. Appl. Meteorol., 18, 532-542, 1979.

Werne, J. and Fritts, D.: Anisotropy in a stratified shear layer, Phys. Chem. Earth Pt. B, 26, 263-268, https://doi.org/10.1016/S14641909(01)00004-1, 2001.

Werne, J. and Fritts, D. C.: Stratified shear turbulence: Evolution and statistics, Geophys. Res. Lett., 26, 439-442, https://doi.org/10.1029/1999GL900022, 1999.

Wilhelm, S., Stober, G., and Chau, J. L.: A comparison of 11year mesospheric and lower thermospheric winds determined by meteor and MF radar at $69^{\circ} \mathrm{N}$, Ann. Geophys., 35, 893-906, https://doi.org/10.5194/angeo-35-893-2017, 2017.

Woodman, R. F.: Coherent radar imaging: Signal processing and statistical properties, Radio Sci., 32, 2373-2391, https://doi.org/10.1029/97RS02017, 1997.

Wüst, S., Offenwanger, T., Schmidt, C., Bittner, M., Jacobi, C., Stober, G., Yee, J.-H., Mlynczak, M. G., and Russell III, J. M.: Derivation of horizontal and vertical wavelengths using a scanning $\mathrm{OH}(3-1)$ airglow spectrometer, Atmos. Meas. Tech. Discuss., https://doi.org/10.5194/amt-2017-350, in review, 2017. 